\title{
Abdômen agudo em equídeos no semiárido da região Nordeste do Brasil ${ }^{1}$
}

\author{
André Flávio Almeida Pessoa², Eldinê Gomes de Miranda Neto², Clarice Ricardo \\ de Macêdo Pessoa ${ }^{2}$, Sara Vilar Dantas Simões ${ }^{2}$, Sérgio Santos de Azevedo ${ }^{2}$ \\ e Franklin Riet-Correa ${ }^{2 *}$
}

\begin{abstract}
Pessoa A.F.A, Miranda Neto E.G., Pessoa C.R.M., Simões S.V.D., Azevedo S.S. \& Riet-Correa F. 2012. [Acute abdomen in equidae in the semiarid of the Brazilian Northeast.] Abdômen agudo em equídeos no semiárido do Nordeste do Brasil. Pesquisa Veterinária Brasileira 32(6):503-509. Hospital Veterinário, Centro de Saúde e Tecnologia Rural, Campus de Patos, Universidade Federal de Campina Grande, Patos, PB 58700-070, Brazil. E-mail: franklin.riet@pq.cnpq.br

The cases of equidae acute abdomen diagnosed in the Veterinary Hospital of the Federal University of Campina Grande, in the semiarid of the Brazilian Northeast were reviewed. From January 2001 to December 2011, 70 (4.5\%) equidae out of 1542 were affected by colic, including 60 horses, 4 mules, and 6 donkeys. Large colon impaction diagnosed in $37.14 \%$ of the cases was the most frequent cause of colic, followed by small colon impaction (10\%) and foreign body in the small colon (7.14\%). In four cases, colics were caused by phytobezoars in the large gut, two of which were associated with the ingestion of large amounts of fresh Prosopis juliflora pods._Six cases of colic by foreign bodies, mainly plastic bags, were observed, five located in the small colon and one in the large colon. Strangulating small intestinal lesions were observed in four cases. Other causes of colic were spasmodic colic (two cases due to gastrointestinal parasites and two due to consumption of home residues), and gastric impaction (three cases). Large colon displacement was diagnosed twice. Laceration of the small colon, cecal torsion, and bloat by ingestion of Manihot esculenta were diagnosed once. The main risk factor for the occurrence of colic was the ingestion of choped Pennisetum purpureum, Brachiaria spp., Sorghum spp. or Echinochloa polystachya (OR=4.03; P=0.007). As a result of the low quality of the foods the frequency of colic was significantly higher during the dry season (second semester) $(\mathrm{OR}=2.61 ; \mathrm{P}<0.01)$. It is concluded that feeding with low quality forages during the dry season contributes with the high frequency of cases of colic in the Brazilian semiarid, and that is necessary to improve food quality and food management to try to decrease the frequency of this syndrome in the region.
\end{abstract}

INDEX TERMS: Colic, equidae, compaction, foreign bodies, phytobezoars.

RESUMO.- Foram revisados os casos de abdômen agudo de origem gastrintestinal em equídeos atendidos no Hospital Veterinário da Universidade Federal de Campina Grande, em Patos, Paraíba. No período de janeiro de 2001 a dezembro de 2010. Setenta (4,5\%) do total de 1542 equídeos atendidos no período apresentaram quadro clínico de

\footnotetext{
${ }^{1}$ Recebido em 7 de outubro de 2011.

Aceito em 12 de fevereiro de 2012.

${ }^{2}$ Hospital Veterinário, Centro de Saúde e Tecnologia Rural (CSTR), Campus de Patos da Universidade Federal de Campina Grande (UFCG), Patos, PB 58700-000, Brasil. *Autor para correspondência: franklin.riet@pq.cnpq.br
}

cólica, sendo 60 equinos, cinco muares e cinco asininos. A compactação de cólon maior foi a causa mais frequente de cólica, diagnosticada em 37,14\% dos casos, seguida por compactação de cólon menor (10\%) e corpo estranho de cólon menor $(7,14 \%)$. Em quatro casos as cólicas foram causadas pela presença de fitobezoares no intestino grosso, sendo dois deles associados ao consumo de vagens de Prosopis juliflora. Em cinco casos foi observada a presença de corpos estranhos no cólon menor e em um caso os corposestranhos foram encontrados no cólon maior, sendo principalmente sacos plásticos. As lesões estrangulantes do intestino delgado foram observadas em quatro casos. Outras 
causas foram cólica espasmódica (dois casos por parasitose e dois por ingestão de resíduos domiciliares), sobrecarga gástrica (três casos) e deslocamento de cólon maior que foi diagnosticado em dois animais. Laceração de cólon menor, torção de ceco, compactação de ceco e timpanismo por consumo de Manihot esculenta foram diagnosticados em uma única ocasião. 0 principal fator de risco para o desenvolvimento de cólicas foi o consumo de Pennisetum purpureum, Brachiaria decumbens, Sorghum spp. ou Echinochloa polystachya picados manualmente ou em picotadeira ou triturados em forrageira $(\mathrm{OR}=4,03 ; \mathrm{P}=0,007)$. Como resultado da baixa qualidade dos alimentos ingeridos, a frequência dos atendimentos de equídeos portadores de cólica foi significativamente maior no segundo semestre (época da seca na região estudada) $(\mathrm{OR}=2,61 ; \mathrm{P}<0,01)$. Concluiu-se que a oferta de volumoso de baixa qualidade na seca contribui para a alta frequência de casos de cólica e que o manejo alimentar tem um papel importante na ocorrência da doença e, por isso, a sua melhoria pode influenciar positivamente na redução do número de casos de cólica em equídeos no semiárido nordestino.

TERMOS DE INDEXAÇÃO: Cólica, equídeos, compactação, corpos estranhos, fitobezoares.

\section{INTRODUÇÃO}

A síndrome cólica é uma causa frequente de óbito em equinos, considerada como uma das principais enfermidades que requerem atendimento veterinário. Os prejuízos econômicos acarretados pela enfermidade são significativos, pois frequentemente implicam em custo elevado com o tratamento e a morte dos animais. Os custos relacionados à cólica foram estimados nos Estados Unidos da América EUA em 1998, com base em um estudo de 28.000 cavalos. 0 valor dos cavalos perdidos foi avaliado em US $\$ 70.000 .000,00$ e o custo total para a indústria equestre durante este ano foi estimado em US \$ 144,000.000,00 (Traub-Dargatz et al. 2001). No Brasil, de acordo com o censo 2009, são criados 5,5 milhões de cavalos, desses 48.366 vivem na Paraíba. Embora a equideocultura e o mercado de produtos para equinos tenham uma importante participação no agronegócio brasileiro (7 bilhões de $\mathrm{R} \$ / \mathrm{ano}$ ) (CNA 2004) dados acerca dos prejuízos relacionados com a cólica não são disponíveis.

De acordo com Godoy \& Texeira Neto (2007), a etiologia da cólica é múltipla e controversa. Em alguns casos a causa pode ser evidente, como na sobrecarga de grãos ou obstrução por corpo estranho, mas muitas vezes a determinação do fator desencadeante torna-se impossivel para o clínico. Para White (1995) a parasitose, a presença de lesões inflamatórias no trato digestivo e a ação de drogas que pertubem a função digestória e o movimento intestinal são as principais causas para o desecadeamento da enfermidade. Radostits et al. (2007) consideram que há diferenças regionais nas causas de cólica e, pela importância da enfermidade, estudos que a caracterizem devem ser incentivados.

Os conhecimentos sobre a epidemiologia e frequência da cólica equina utilizados atualmente por veterinários no Brasil foram produzidos, na sua maioria, em estudos reali- zados em outros países, principalmente nos EUA. Estudos realizados em clínicas e hospitais veterinários naquele país indicam que a obstrução simples, a cólica espasmódica e as compactações são as categorias mais comumente diagnosticadas (White 1990, White 2005). No entanto, estudos que caracterizem a síndrome cólica em equinos e outros equídeos nas diferentes regiões do Brasil são raros ou inexistentes, em um desses realizado com animais da cavalaria militar no Rio de Janeiro a cólica simples por dilatação gástrica foi a mais frequente (Laranjeira et al. 2009).

Informações acerca da incidência, mortalidade e fatores de riscos são úteis para o clínico na tomada de decisões e na adoção de intervenções para a prevenção de novos casos. Este artigo teve como objetivo identificar a epidemiologia e os principais tipos de cólica diagnosticados no Hospital Veterinário da Universidade Federal de Campina Grande em equinos, asininos e muares provenientes da Paraíba e estados vizinhos.

\section{MATERIAL E MÉTODOS}

Foram revisados os prontuários de casos de cólica gastrointestinal em equídeos atendidos no Hospital Veterinário da Universidade Federal de Campina Grande (UFCG), em Patos, no período de janeiro de 2001 a dezembro de 2010, mediante levantamento de fichas clínicas e de necropsias arquivadas. Foram avaliados os dados de identificação do animal, anamnese, exame físico e tipo de tratamento adotado (conservador ou cirúrgico), assim como o desfecho do caso (alta ou óbito) e o tipo de cólica. A classificação do tipo de cólica foi realizada segundo Radostitis et al. (2007). Foram classificados como cólica de causa desconhecida aqueles nos quais não foi possível identificar o fator desencadeante. Foi realizada a análise dos fatores de risco em um estudo caso-controle, considerando como casos todos os equídeos com cólica e como controles o mesmo número de equinos, asininos e muares escolhidos ao acaso entre os animais atendidos por outras causas e isentos da síndrome cólica. As variáveis consideradas foram espécie, sexo, idade, fonte de água, sazonalidade, tratamento para ectoparasitas e endoparasitas, tipo de manejo, raça, tipo de concentrado e tipo de volumoso. A relação entre número de horas do início da síndrome cólica até a internação hospitalar e o desfecho do caso também foi avaliada. As variáveis foram submetidas a análise univariada pelo teste de qui-quadrado ou teste exato de Fisher, com nível de significância de $5 \%$, onde cada variável independente foi cruzada com a variável dependente (casos de cólica), e foi realizada uma estimativa pontual e intervalar da Odds ratio (OR) com intervalo de confiança de 95\% (Thrusfield 2007).

\section{RESULTADOS}

Os equídeos com cólica eram provenientes de municípios da Paraíba, Pernambuco e Rio Grande do Norte e os asininos e muares provenientes do município de Patos, Paraíba. A faixa etária dos animais variou de 17 dias a 23 anos. No Quadro 1 são apresentados os números de equídeos atendidos, com e sem cólica, e a letalidade observada. Não houve diferenças significativas na letalidade por cólica entre as espécies estudadas $(\mathrm{P}=0,587)$. Foi constatado que os equídeos afetados por cólica tem 6,98 mais chance de ir a óbito que os portadores de outras causas analisadas em conjunto (Quadro 2). Os equinos estudados eram das raças Quarto de Milha, Mestiços, Puro Sangue Inglês, Pônei, Paint Horse, 
Quadro 1. Número de equídeos atendidos, total de mortes, número de atendimentos por cólica e mortes por cólica no HV-UFCG (2001-2010)

\begin{tabular}{ccccc}
\hline Espécies & Atendimentos Mortes $^{\mathrm{a}}(\%)$ & $\begin{array}{c}\text { Atendimentos } \\
\text { por cólica }^{\mathrm{b}}(\%)\end{array}$ & $\begin{array}{c}\text { Mortes por } \\
\text { cólica }^{\mathrm{c}}(\%)\end{array}$ \\
\hline Equinos & 1313 & $149(11,35)$ & $60(4,57)$ & $38(63,3)$ \\
Asininos & 177 & $17(9,6)$ & $5(3,39)$ & $2(40)$ \\
Muares & 52 & $8(15,38)$ & $5(7,7)$ & $3(60)$ \\
Total & 1542 & $174(11,28)$ & $70(4,54)$ & $43(61,43)$ \\
${ }^{\mathrm{a}} \mathrm{P}=0,502 ;{ }^{\mathrm{b}} \mathrm{P}=0,290 ;{ }^{\mathrm{c}} \mathrm{P}=0,587$. & &
\end{tabular}

Quadro 2. Análise de associação entre a ocorrência de cólica e o desfecho, com o respectivo valor de Odds ratio (OR), intervalo de confiança de $95 \%$ (IC 95\%) e a probabilidade de ocorrência ao acaso $(P)$

\begin{tabular}{|c|c|c|c|c|}
\hline $\begin{array}{l}\text { Ocorrência de } \\
\text { cólica }\end{array}$ & $\begin{array}{c}\text { № de } \\
\text { equídeos (\%) }\end{array}$ & $\begin{array}{c}\text { № de } \\
\text { mortes (\%) }\end{array}$ & $\begin{array}{l}\text { Odds ratio } \\
\text { (IC } 95 \% \text { ) }\end{array}$ & $\mathrm{P}$ \\
\hline $\mathrm{Nã}$ & $70(50)$ & $13(18,6)$ & 1 & \\
\hline Sim & $70(50)$ & $43(61,4)$ & $6,98(3,23-15,09)$ & $<0,001$ \\
\hline
\end{tabular}

Árabe, Apallosa e animais sem raça definida. No Quadro 3 são apresentadas as diferentes causas de cólica identificadas. As diversas causas de cólica ocorreram em animais de diferentes idades, exceto a cólica espasmódica por parasitose que afetou exclusivamente animais de menos de dois anos que apresentaram contagem de 3000 e 6660 ovos de helmintos da família Strongyloidea por gramo de fezes. Dois casos de cólica espasmódica por ingestão de restos de alimentos domiciliares ocorreram em animais adultos.

Dos 37 casos de compactação de intestino grosso, que estão listados no Quadro 3, como compactação de cólon maior, compactação de cólon menor e presença de fitobezoares, 18 (24,3\% do total de animais com cólica) foram associados ao consumo de capim elefante (Pennisetum purpureum) como fonte de volumoso. Em quatro casos o capim elefante era administrado junto com rolão de milho (milho ainda no sabugo moído com palha). Outros capins consumidos foram braquiária (Brachiaria spp), sorgo (Sorghum spp.) e capim mandante (Echinochloa polystachya). A idade de corte do capim não foi informada e as formas de ofe-

Quadro 3. Diagnósticos de cólica em equídeos registrados no HV da UFCG (janeiro de 2001 a dezembro de 2010)

\begin{tabular}{lcccc}
\hline \multicolumn{1}{c}{ Diagnóstico } & \multicolumn{2}{c}{ Espécie/no de casos } & Total \\
\cline { 2 - 4 } & Equina & Asinina & Muar & \\
\hline Cólica espasmódica & 3 & 1 & & 4 \\
Cólica fermentativa & 1 & & & 1 \\
Compactação de ceco & 1 & & & 1 \\
Compactação de cólon maior & 23 & 2 & 1 & 26 \\
Compactação de cólon menor & 6 & & 1 & 7 \\
Corpo estranho cólon maior & 1 & & & 1 \\
Corpo estranho cólon menor & 5 & & & 5 \\
Deslocamento de cólon maior & 1 & & 1 & 2 \\
Fitobenzoário & 3 & & 1 & 4 \\
Ruptura de cólon menor & 1 & & & 1 \\
Síndrome Cólica & 7 & 2 & 1 & 10 \\
Sobrecarga gástrica & 3 & & & 3 \\
Torção de ceco & 1 & & & 1 \\
Lesão estrangulate do intestino delgado & 4 & & & 4 \\
TOTAL & 60 & 5 & 5 & 70
\end{tabular}

recimento foram: picado manualmente ou em picotadeira; e triturado em máquina. Em dois asininos a compactação foi associada ao consumo de palha de feijão (Phaseolus vulgaris). Em nove casos de compactação não foi informado o alimento ingerido pelos animais.

0 consumo de volumoso de P. purpureum, Brachiaria spp., Sorghum spp. ou E. polystachya foi fator de risco importante para o desenvolvimento de cólica $(\mathrm{OR}=4,03$; $\mathrm{P}=0$,007) (Quadro 4).

Em quatro casos, as cólicas foram associadas à formação de fitobezoares: em um equino criado em sistema extensivo com pastagem composta por capim buffel (Cenchrus ciliaris); em um muar criado em sistema intensivo e alimentado com palha de feijão (Phaseolus vulgaris); e em dois equinos que tiveram acesso a grande quantidade de vagens de algaroba (Prosopis juliflora). Nestes dois últimos casos os animais tinham sido soltos à noite em uma área contendo algaroba (Prosopis juliflora) em fase de frutificação, havendo quantidade considerável de vagens disponíveis. Nas necropsias de três destes animais os fitobezoares estavam localizados no cólon maior, anterior à flexura pélvica No muar, o fitobezoar era único e estava localizado na passagem do cólon dorsal direito para o segmento transverso do cólon menor. Nos outros três equinos os fitobezoares estavam localizados no cólon maior, anterior à flexura pélvica; desses apenas um apresentou dois fitobenzoares, nos outros dois estes também eram únicos. Em dois equinos os fitobezoares eram constituídos por fibras vegetais e sementes de algaroba. No terceiro equino o fitobezoar era composto de fibras mal digeridas e no muar por palha de feijão.

Dois casos de compactação do cólon maior foram associados à hipomotilidade colônica iatrogênica; um deles pelo uso de formamidina em banho carrapaticida e outro pela utilização de imidocarb para controle de babesiose.

Os casos de cólica obstrutiva estrangulante com comprometimento vascular incluindo deslocamento de cólon maior, torção de ceco e lesão estrangulativa do intestino delgado (encarceramento, torção de alças e da raiz mesentérica) representaram $8,6 \%$ dos casos totais de cólica, com letalidade de $100 \%$. Foram observados dois casos de encarceramento de intestino delgado, um por encarceramento em fenda mesentérica e outro por hérnia inguino-escrotal indireta.

Corpos estranhos no cólon maior e menor foram observados em cinco cavalos e em um pônei. Cinco destes foram submetidos a laparotomia exploratória com enterotomia. Em cinco equinos o corpo estranho estava localizado no cólon menor e em um ponei no cólon maior. Um equino, de 1,5 anos, que apresentou obstrução por corpo estranho no colón menor foi tratado clinicamente; o corpo estranho não metálico estava localizado na passagem do cólon menor para o reto e foi realizada a retirada deste através de palpação retal; mas aos seis anos de idade apresentou outro corpo estranho de mesma natureza, localizado, também, no cólon menor. 0 corpo estranho foi extraído cirurgicamente, porém o animal morreu no pós-operatório. Os outros animais apresentavam idades entre cinco e 10 anos, viviam em zona urbana e tinham acesso a ruas e terrenos 


\begin{tabular}{|c|c|c|c|c|}
\hline Variável & № de equídeos (\%) & № de animais com cólica (\%) & Odds ratio (IC 95\%) & $\mathrm{P}$ \\
\hline \multicolumn{5}{|l|}{ Espécie } \\
\hline Asinino & $13(9,2)$ & $5(38,4)$ & 1 & \\
\hline Equino & $121(86,4)$ & $60(49,6)$ & $1,57(0,43-5,93)$ & 0,638 \\
\hline Muar & $6(4,4)$ & $5(83,3)$ & $8,00(0.54-245,79)$ & 0,410 \\
\hline \multicolumn{5}{|l|}{ Sexo } \\
\hline Fêmea & $55(39,3)$ & $27(49,1)$ & 1 & \\
\hline Macho & $85(60,7)$ & $42(49,4)$ & $1,01(0,49-2,11)$ & 0,892 \\
\hline \multicolumn{5}{|l|}{ Idade } \\
\hline$>72$ meses & $57(43)$ & $25(43,9)$ & 1 & \\
\hline 32 a 72 meses & $42(31,5)$ & $22(52,4)$ & $1,41(0,59-3,39)$ & 0,525 \\
\hline 0 a 31 meses & $34(25,5)$ & $18(52,9)$ & $1,44(0,56-3,69)$ & 0,534 \\
\hline \multicolumn{5}{|l|}{ Fonte de água } \\
\hline Não tratada & $71(64,5)$ & $25(32,5)$ & 1 & \\
\hline Tratada & $39(35,5)$ & $20(51,3)$ & $1,94(0,81-4.64)$ & 0,151 \\
\hline \multicolumn{5}{|l|}{ Tratamento anterior } \\
\hline Não & $35(29,2)$ & $12(34,3)$ & 1 & \\
\hline Sim & $85(70,8)$ & $41(48,2)$ & $1,79(0,73-4,39)$ & 0,232 \\
\hline \multicolumn{5}{|l|}{ Tratamento para ectoparasitas } \\
\hline Sim & $10(15,4)$ & $2(20)$ & 1 & \\
\hline Não & $55(84,6)$ & $27(49,1)$ & $3,86(0,66-29,10)$ & 0,165 \\
\hline \multicolumn{5}{|l|}{ Tratamento para endoparasitas } \\
\hline Não & $43(41,4)$ & $17(39,5)$ & 1 & \\
\hline Sim & $61(58,6)$ & $27(44,3)$ & $1,21(0,51-2,90)$ & 0,780 \\
\hline \multicolumn{5}{|l|}{ Manejo } \\
\hline Extensivo & $27(21,1)$ & $8(29,6)$ & 1 & \\
\hline Intensivo ou semi-intensivo & $101(78,9)$ & $53(52,5)$ & $2,62(0,97-7,25)$ & 0,058 \\
\hline \multicolumn{5}{|l|}{ Raça } \\
\hline QM/Mest QM & $43(36,5)$ & $22(51,2)$ & $1,61(0,61-4,28)$ & 0,406 \\
\hline SRD & $37(31,3)$ & $20(54,1)$ & $1,80(0,65-5,02)$ & 0,301 \\
\hline Outras & $38(32,2)$ & $15(39,5)$ & 1 & \\
\hline \multicolumn{5}{|l|}{ Concentrado } \\
\hline Ração balanceada & $31(29,9)$ & $14(45,2)$ & $1,65(0,34-8,33)$ & 0,718 \\
\hline Ração balanceada + FM + FT & $12(11,5)$ & $4(33,3)$ & 1 & \\
\hline $\mathrm{FM}+\mathrm{FT}^{\mathrm{a}}$ & $61(58,6)$ & $34(55,7)$ & $2,52(0,60-11,31)$ & 0,270 \\
\hline \multicolumn{5}{|l|}{ Volumoso } \\
\hline Capimb & $60(48)$ & $35(58,3)$ & $4,03(1,42-11,74)$ & $0,007 *$ \\
\hline Feno & $4(3,2)$ & $2(50)$ & $2,88(0,23-36,36)$ & 0,561 \\
\hline Pasto nativo & $31(24,8)$ & $8(25,8)$ & 1 & \\
\hline Cynodon spp. & $13(10,4)$ & $4(30,8)$ & $1,28(0,24-6,52)$ & 0,727 \\
\hline Outros & $17(13,6)$ & $10(58,8)$ & $4,11(0,99-17,76)$ & 0,051 \\
\hline \multicolumn{5}{|l|}{ Época do ano } \\
\hline Janeiro-junho & $64(45,4)$ & $23(35,9)$ & 1 & \\
\hline Julho-dezembro & $77(54,6)$ & $47(61,0)$ & $2,61(1,25-5,49)$ & $0,009^{*}$ \\
\hline
\end{tabular}

${ }^{\mathrm{a}} \mathrm{FM}=$ Farelo de milho, FT $=$ farelo de trigo, ${ }^{\mathrm{b}}$ Capim = Pennisetum purpureum, Brachiaria spp., Sorghum spp. e Echinochloa polystachya. * Associação significativa.

não cercados, facilitando assim o contato com corpos estranhos como sacolas plásticas. Em quatro dos cinco equinos que apresentaram corpo estranho no colón menor ocorreu ruptura no local da enterotomia e os animais morreram. $\mathrm{O}$ outro equino recuperou-se. Em quatro desses casos os corpos estranhos eram compostos por material não metálico (sacola plástica), e em um por material metálico e não metálico (emaranhado de sacola plástica e arame). Sacola plástica também foi a causa da obstrução no cólon maior em um pônei que se recuperou.

Sobrecarga gástrica foi diagnosticada em três equinos. Em dois tinha sido oferecido grande quantidade de concentrado de uma só vez e, em seguida, os animais foram submetidos a exercícios físicos; nesses casos houve ruptura do estômago e morte. 0 outro animal tinha ingerido grande quantidade de concentrado após uma cirurgia eletiva oca- sionando sobrecarga gástrica, mas que foi sanada mediante lavagem e esvaziamento gástrico

Cólica fermentativa por consumo de tubérculos de mandioca (Manihot esculenta) foi diagnosticada em um equino e causou formação de gases no trato gastrointestinal. $\mathrm{Na}$ necropsia observou-se dilatação acentuada dos segmentos intestinais com presença de odor sugestivo de fermentação dos tubérculos desta planta.

Trinta e cinco animais deram entrada no Hospital Veterinário de seis a 24 horas após os sinais de cólica terem sido evidenciados; destes 24 morreram. De 25 casos recebidos 24 a 96 horas após o início da enfermidade, 10 morreram. De quatro casos recebidos com evolução clínica acima de 96 horas, três morreram. Seis casos nos quais o tempo de evolução não foi informado também evoluíram para a morte. Vinte e sete casos $(38,57 \%)$ evoluíram para a 
cura e 43 animais (61,43\%) morreram. Na análise do período entre o início dos sinais e o momento do atendimento no Hospital Veterinário com o respectivo desfecho do quadro clínico (óbito ou recuperação) (Quadro 5), observou-se que os animais acometidos por abdômen agudo apresentaram maior frequência de óbito do que os acometidos por outras doenças $(\mathrm{P}=0,008)$.

\begin{tabular}{|c|c|c|c|c|}
\hline $\begin{array}{c}\text { Evolução } \\
\text { (horas) }\end{array}$ & $\begin{array}{c}\text { № de } \\
\text { eqüídeos (\%) }\end{array}$ & $\begin{array}{c}\text { № mortes } \\
\text { por cólica (\%) }\end{array}$ & $\begin{array}{l}\text { Odds ratio } \\
\text { (IC 95\%) }\end{array}$ & $\mathrm{P}$ \\
\hline 6 a 24 & $42(32)$ & $28(66,7)$ & $11,50(3,89-35,29)$ & $<0,001$ \\
\hline 25 a 96 & $35(26,7)$ & $13(37,1)$ & $3,40(1,11-10,65)$ & 0,030 \\
\hline$>96$ & $54(41,3)$ & $8(14,8)$ & 1 & \\
\hline
\end{tabular}

A maioria dos animais, 41 (58,57\%), já havia recebido tratamento anterior antes da chegada ao Hospital Veterinário. Apenas 12 proprietários ou tratadores disseram não ter tratado o animal previamente para cólica e 17 não informaram se houve tratamento. Doze animais foram submetidos à laparotomia exploratória para diagnóstico e/ ou tratamento; desses, seis (50\%) foram eutanasiados no trans-operatório, cinco (42\%) foram a óbito no pós-operatório, com ruptura de alça intestinal ou peritonite, e um teve alta hospitalar após 30 dias.

Quanto ao manejo, 34 (48,57\%) animais eram mantidos presos durante o dia e soltos a noite (semi-intensivo); 19 $(27,14 \%)$ eram mantidos em baias durante 24 horas (intensivo); oito $(11,43 \%)$ estavam soltos a campo (extensivo) e em nove casos $(12,86 \%)$ não foi informado o manejo utilizado. Em dois casos os proprietários informaram ter ocorrido mudança do manejo extensivo para o intensivo antes da ocorrência de cólica. A análise do tipo de manejo como possível fator de risco associado à cólica_não foi estatisticamente significativa (OR=2,62; $\mathrm{P}=0,058$ ) (Quadro 4).

Em relação à ração concentrada $(\mathrm{RC})$, milho em grão, milho moído ou farelo de milho, ocasionalmente misturados com farelo de trigo, foram os alimentos mais utilizados (39 animais). Dezenove animais alimentavam-se de ração balanceada comercial (RBC). Em seis casos misturava-se a RBC com farelo de milho e/ou farelo de trigo e seis animais não tinham acesso a RC. A quantidade de RC oferecida variou de 0,5 a $1,5 \%$ do peso vivo do animal. Não houve associação entre o consumo de RC e a ocorrência de cólica (Quadro 4).

Quanto ao fornecimento de água, foi informada apenas a fonte, mas o regime de fornecimento e o volume da água e do cocho não foram informados. A fonte mais freqüente utilizada foi água oriunda de estações de tratamento das cidades. Também não houve associação entre a fonte de água e a ocorrência de cólica (Quadro 4).

Trinta proprietários relataram adotar controle anti-helmíntico, com utilização de vermífugos e um relatou praticar exame coproparasitológico para monitoração. 0 princípio ativo dos vermífugos utilizados foi, em todos os casos, a ivermectina. Dos 24 proprietários que relataram a data do último tratamento, 17 tinham tratado os animais com anti-helmínticos há menos de 90 dias. 0 intervalo entre tratamentos não foi informado. A realização de controle de ectoparasitas foi informada em apenas dois casos (um com Fipronil e outro com Amitraz). Não houve associação entre o controle de endo e ectoparasitas e o desencadeamento de cólica (Quadro 4).

Quanto à sazonalidade, foram consideradas duas estações: chuva, de janeiro a junho; e seca, de julho a dezembro. A frequência dos atendimentos por cólica foi maior no segundo semestre (época da seca) (OR=2,61; $P=0,009)$ (Quadro 4).

\section{DISCUSSÃO}

Nesse estudo verificou-se que os tipos de cólica mais frequentes no Hospital Veterinário (HV) da Universidade Federal de Campina Grande (UFCG), em Patos, no período de janeiro de 2001 a dezembro de 2010, foram a compactação do cólon maior, seguido por compactação do cólon menor, obstrução por corpo estranho no cólon menor, e cólica espasmódica. Em clínicas de referência nos Estados Unidos da América (EUA), a compactação do cólon maior constituem cerca de $13 \%$ dos casos de cólica atendidos e a mortalidade nesses casos atinge os 20\% (Dabareiner \& White 1995). Neste trabalho, a frequência alta de compactação do cólon maior $(37,14 \%$ dos casos de cólica) verificada é, provavelmente, reflexo do tipo de alimentação oferecida aos animais, sendo que 18 casos (48,65\% do total de animais com cólica por compactação) estiveram associados ao consumo de capim elefante. Constatou-se mediante o estudo estatístico que os animais que consumiam algum tipo de capim triturado ou picado, sejam eles elefante, braquiária, sorgo ou capim mandante, foram mais propícios a desencadear o quadro clínico de cólica. 0 capim elefante é bem difundido no Brasil devido a sua alta produtividade e boa adaptabilidade (Pupo 1980). Pelo elevado conteúdo de fibra, em particular quando ultrapassa 180 dias de crescimento, seu consumo tem sido associado à quadros de cólica por compactação (Silva Neto 2007). Além das compactações de cólon maior associadas à esses volumosos, houve dois casos desse distúrbio ocasionados pelo consumo de palha de feijão, que também é um volumoso de baixa qualidade. A qualidade do volumoso, a disponibilidade de água, problemas de dentição, falta de exercício e mudanças recentes no manejo (extensivo para intensivo) podem ser causas de cólica por compactação (Keller \& Horney 1985, Schumacher \& Mair 2002, Thomassian 2005, Moore 2005). 0 tempo de permanência do alimento nos diversos segmentos do trato digestório do cavalo é multifatorial, e inclui variáveis tais como: a individualidade, o tipo de atividade física e a natureza da dieta (Meyer 1995).

Os 12 casos de obstrução do cólon menor, por compactação ou corpo estranho, representaram $17,14 \%$ das causas de cólica. Quatro desses casos foram associados, também, a ingestão de capim elefante, cinco a corpos estranhos e em dois não foi estabelecida a causa. Nos EUA, as obstruções de cólon menor são menos freqüentes e representam menos de $5 \%$ dos casos de cólica em equinos internados em hos- 
pitais de referência (Khan 2010). No caso de compactação é possível que essa diferença seja devida às melhores condições de manejo empregadas nos EUA e uma assistência veterinária mais especializada, proporcionando resolução dos casos de compactação sem necessidade de internação. Neste estudo o segundo tipo de cólica mais frequente foi a compactação de cólon menor (7 casos), e corpos estranhos no cólon menor foram a terceira causa com 5 casos. Também foi observada obstrução do cólon maior por corpo extranho em um equino. De acordo com Gay et al. (1979), as cólicas obstrutivas por corpo estranho ocorrem, geralmente, em equinos jovens, devendo ser considerado como diagnóstico diferencial para casos de cólicas obstrutivas sem estrangulação em pacientes com menos de três anos. No entanto, essa faixa etária não foi a mais afetada neste estudo onde os animais apresentaram idade variada com um maior número de adultos acometidos.

Além do volumoso de má qualidade, a sazonalidade foi um fator significante, sendo associada à maior frequência de cólica na época da seca $(\mathrm{OR}=2,61 ; \mathrm{P}=0,009)$. Este resultado reflete as más condições de alimentação na época seca, durante a qual ocorre oferta de volumosos de má qualidade, além de maior administração de ração concentrada e maiores possiblidades de ingestão de corpos estranhos. A permanência dos equinos em zonas urbanas nesta época do ano facilita, também, o contato com corpos estranhos como sacolas plásticas. Cox et al. (2007) encontraram associação entre cólica por compactação em asininos e sazonalidade, sendo mais frequente nas estações de outono e inverno quando há mudanças na qualidade da dieta e redução do exercício físico.

Fitobezoares compostos por sementes de algaroba e fibras de má qualidade não digeridas foram encontrados em dois equinos. A patogênese da formação do fitobezoares das vagens da algaroba é desconhecida, porém de acordo com Knight \& Walter (2001), sementes e vagens de Prosopis glandulosa quando em contato com meio aquoso formam uma massa viscosa que interfere na digestão das fibras, o que pode ser também o caso da algaroba. Outro caso de obstrução por fitobezoar foi associado ao consumo de capim buffel e um caso em muar foi relacionado ao consumo de palha de feijão. A associação entre fitobezoares e fibras de baixa qualidade é reportada também em bovinos criados no semiárido em épocas de pouca disponibilidade de forragem (Afonso et al. 2008).

Dois casos de cólica espasmódica foram associados à parasitose em equinos não vermifugados. A penetração e migração de larvas de Strongylus vulgaris na parede intestinal e de vasos causam alterações da peristalse com espasmos ou distensão intestinal em virtude da perda da atividade propulsiva, resultando em dor (Berry et al. 1986, Thomassian 2005, Radostitis et al. 2007). Qualquer outro fator considerado como desencadeante de cólica espasmódica como excitação ou estresse não foi identificado no estudo em tela. Segundo Urquhart et al. (1998) é difícil determinar a importância de larvas migratórias de $S$. vulgaris em casos de cólica, mas, geralmente, quando as infecções parasitárias são eficazmente controladas a incidência de cólica diminui acentuadamente. Comprovando a influência de diferenças regionais na ocorrência de diversos tipos de cólica, as cólicas espasmódicas neste trabalho representaram 5,71\% do total, enquanto que em equinos do Reino Unido e Canadá esta causa é mais frequente, chegando a $72 \%$ e 16,9\%, respectivamente (Proudman 1992, Abutarbush et al. 2005).

Nos equinos deste trabalho foram observados somente três casos de dilatação gástrica seguida de ruptura gástrica, associados à alimentação com grãos. Em um estudo epidemiológico realizado em equinos de cavalaria militar no Rio de Janeiro a cólica gástrica foi à causa de maior incidência, contribuindo com 78,1 a $86,6 \%$ dos casos (Laranjeira et al. 2009). Essas diferenças podem estar associadas aos tipos de manejo utilizados nas diferentes regiões. Foi diagnosticado um caso isolado de cólica fermentativa por consumo de tubérculos de Manihot esculenta. A mandioca é uma planta cianogênica que tem produzido intoxicações em ruminantes no semiárido quando suas raízes ou resíduos são consumidos em grande quantidade (Riet-Correa et al. 2006).

Neste estudo foi observado um índice de letalidade de 61,43\%. Em Hospitais Escolas Veterinários de outros países a letalidade é menor, podendo atingir níveis tão baixos quanto $6,7 \%$ nos EUA (Tinker et al. 1997) ou de $34,4 \%$ no Canadá (Abutarbush et al. 2005 ). A taxa de óbito constatada neste trabalho foi, também, consideravelmente superior a de outros hospitais de equinos em outros estados (Alves 2011), o que evidencia a necessidade de uma melhoria continuada do serviço cirúrgico emergencial e dos cuidados intensivistas em casos de síndrome cólica. 0 atendimento imediato dos casos de cólica por veterinários qualificados, com o tratamento e decisões adequadas, se conservador ou cirúrgico, certamente irão influenciar nos dados de incidência de cólica e taxa de óbito observadas nos equinos neste estudo. De modo geral, a taxa de sobrevivência de equinos com cólica é inversamente proporcional à duração dos sinais clínicos (Parks et al. 1989). No entanto, neste trabalho animais atendidos de 6 a 24 e de 25 a 96 horas após o início da cólica tiveram maior chance de óbito do que os atendidos após 96 horas. Este resultado pode ser devido à maior taxa de óbito das afecções agudas com dor intensa e, provavelmente, reflete o fato de que os animais com sinais mais graves são encaminhados ao Hospital antes dos que apresentam sinais menos graves, portanto estes últimos têm maiores possibilidades de sobrevivência.

\section{CONCLUSÃO}

Concluiu-se que, no semiárido brasileiro, a oferta de volumoso de baixa qualidade na seca contribui para o aumento do número de casos de cólica e que o manejo alimentar tem um papel importante na ocorrência de cólicas e, por isso, a sua melhoria pode influenciar positivamente na redução do número de casos da doença. em equídeos no semiárido nordestino.

Agradecimentos.- Ao professor Geraldo Eleno Alves pela revisão do manuscrito.

\section{REFERÊNCIAS}

Abutarbush S.M., Carmalt J.L. \& Shoemaker R.W. 2005. Causes of gastrointestinal colic in horses in western Canada. Can. Vet. J. 46:800-805. 
Afonso J.A.B., Pereira A.L.L., Vieira A.C.S., Mendonça C.L., Costa N.A. \& Souza M.I. 2008. Alterações clínicas e laboratoriais na obstrução gastrintestinal por fitobezoares em bovinos. Revta Bras. Saúde Prod. Anim. 9:91-102.

Alves G.E.S. 2011. Comunicação pessoal (Escola de Veterinária, Universidade Federal de Minas Gerais, Belo Horizonte. E-mail: geufmg@gmail. com).

Berry C.R., Merritt A.M., Burrows C.F., Campbell M. \& Drudge J.H. 1986. Evaluation of the myoelectrical activity of the equine ileum infected with Strongylus vulgaris larvae. Am. J. Vet. Res. 47(1):27-30

Cox R., Proudman C.J., Trawford A.F., Burden F. \& Pinchbeck G.L. 2007. Epidemiology of impaction colic in donkeys in the UK. BMC Veterinary Research. 3:1, doi: 10.1186/1746-6148-3-1

Dabareiner R.M. \& White N.A. 1995. Large colon impaction in horses: 147 cases (1985-1991). J. Am. Vet. Med. Assoc. 206(5):679-685.

Gay C.C., Speirs V.C., Christie B.A., Smith B. \& Parry B. 1979. Foreign body obstruction of the colon in six horses. Equine Vet. J. 11:60-63.

Godoy R.F. \& Texeira Neto A.R. 2007. Cólica em equinos, p.571-621. In: Riet-Correa F., Mendez M.C., Schild A.L., Lemos R.A.A. (Eds), Doenças de Ruminantes e Equinos. Vol.2. 3a ed. Pallotti. Santa Maria, RS.

Kahn C.M. 2010. The Merck Veterinary Manual. $10^{\text {th }}$ ed. Merial Limited, Duluth, p.226-244.

Keller S.D. \& Horney F.D. 1985. Diseases of the equine small colon. Compend. Contin. Educ. Pract. Vet. 7:113-120.

Knight A.P. \& Walter R.G. 2001. A Guide to Plant Poisoning of Animals in North America. Teton NewMedia., Jackson, WY, p.94-95.

Laranjeira P.V.E.H., Almeida F.Q., Pereira M.J.S., Lopes M.A.F., Campos C.H.C., Caiuby L.C.A.B. \& Souza P.N.B. 2009. Perfil e distribuição da sindrome cólica em equinos em três unidades militares do Estado do Rio de Janeiro, Brasil. Ciência Rural 39(4):1108-1115.

Meyer H. 1995. Alimentação de Cavalos. Livraria Varela, São Paulo. 303p.

Moore R.M. 2005. Treatment of luminal obstructions of the large and small colon in horses. Proc. American Association of Equine Practitioners Focus Meeting, Québec, Canada. Versão eletrônica.

Parks A.H., Doran R.E., White N.A., Allen D. \& Baxter G.M. 1989. Ileal impaction in the horse: 75 cases. Cornell Vet. 79:83-91.
Pupo N.I.H. 1980. Manual de Pastagem e Forrageira: Formação, Conservação, Utilização. Ed. Instituto Campineiro de Estudo Agrícola, Campinas, SP, p.78-83.

Proudman C.J. 1992. A two year, prospective survey of equine colic in general practice. Equine Vet. J. 24:90-93.

Radostits O.M., Gay C.C., Hinchdliff K.W. \& Constable P.D. 2007. Veterinary Medicine. $10^{\text {th }}$ ed. W.B. Saunders, London, p.215-258.

Riet-Correa F., Medeiros R.M.T. \& Dantas A.F.M. 2006. Plantas Tóxicas da Paraíba. Centro de Saúde e Tecnologia Rural, Patos, PB, SEBRAE/PB. 58 .

Schumacher J. \& Mair T.S. 2002. Small colon obstructions in the mature horse. Equine Vet. Educ. 14:19-28.

Silva Neto P.C. 2007. Relato de caso clínico: compactação de cólon maior causada pela ingestão de capim napier. Monografia, Faculdade de Jaguariúna, SP. <http://www.equalli.com.br/upload/textos/pdf/prt/125. pdf> Acessado em 29 set. 2009.

Tinker M.K., White N.A., Lessard P., Thatcher C.D., Pelzer K.D., Davis B. \& Carmel D.K.1997. Prospective study of equine colic incidence and mortality. Equine Vet. J. 29(6):448-453.

Thomassian A. 2005. Enfermidade dos Cavalos. $4^{\mathrm{a}}$ ed. Editora Varela, São Paulo.

Thrusfield M. 2007. Veterinary Epidemiology. $3^{\text {rd }}$ ed. Blackwell Science, Oxford. 610p.

Urquhart G.M., Armour J., Ducan J.L., Dunn A.M. \& Jennings F.W. 1998. Parasitologia Veterinária. $2^{\mathrm{a}}$ ed., Guanabara Koogan, Rio de Janeiro, p.3-120.

Traub-Dargatz J.L., Kopral C.A., Seitzinger A.H., Garber L.P., Forde K. \& White N.A. 2001. Estimate of the national incidence of and operation-level risk factors for colic among horses in the United States, spring 1998 to spring 1999. J. Am. Vet. Med. Assoc. 219(1):67-71.

White N.A. 1990. Epidemiology and etiology of colic, p. 49-64. In: White N.A. (Ed) The equine acute abdomen. Lea \& Febiger, Philadelphia.

White N.A. 1995. Epidemiology of equine colic. Anais Ciclo Internacional de Cólica Equina, Jaboticabal, SP, p.26-27.

White N.A. 2005. Prevalence, Demographics and Risk Factors for Colic. Proc. American Association of Equine Practitioners Focus Meeting, Québec, Canada. Versão eletrônica. 